\title{
POSSIBILIDADES DE RESSIGNIFICAÇÕES NAS PRÁTICAS PEDAGÓGICAS EMERGENTES DA GAMIFICAÇÃO'
}

\author{
POSSIBILITIES OF NEW MEANINGS IN THE TEACHING PRACTICES EMERGING \\ FROM GAMIFICATION
}

\section{POSIBILIDADES DE RESIGNIFICACIONES EN LAS PRÁCTICAS PEDAGÓGICAS EMERGENTES DE LA GAMIFICACIÓN}

\section{Cristina Martins ${ }^{1}$, Lucia Maria Martins Giraffa ${ }^{23}$}

\section{RESUMO}

Este artigo apresenta o resultado de uma investigação relacionado a práticas pedagógicas e gamificação, onde discutimos as possibilidades de ressignificações da prática que emergem das experiências vivenciadas por professores com um modelo de desenvolvimento de atividades gamificadas, na perspectiva da Educação Continuada em serviço. O aporte teórico utilizado considerou os princípios sociointeracionistas, a teoria do pensamento complexo, a cibercultura e as concepções relacionadas ao desenvolvimento de competências. A pesquisa de cunho qualitativo, de caráter exploratório, apoiou-se num estudo de caso cujos sujeitos eram professores de uma instituição de ensino privada, atuantes nos Anos Iniciais do Ensino Fundamental da Educação Básica. Os instrumentos de coleta de dados da pesquisa foram: questionário online autoaplicável, relato autorreflexivo e entrevista semiestruturada. Os achados da pesquisa mostraram que, apesar de os games (jogos digitais) fazerem parte do cotidiano da atualidade, os sujeitos de pesquisa compreendiam parcialmente a concepção de gamificação. Após a vivência do experimento formativo, demonstraram maior entendimento sobre o conceito e possíveis aplicações práticas e, especialmente, perceberam a potencialidade da aproximação entre os hábitos de lazer e os hábitos de estudo.

PALAVRAS-CHAVE: Gamificação. Práticas pedagógicas. Educação Básica.

\begin{abstract}
This article presents the result of an investigation into teaching practices and gamification, where we discuss the possibilities of new meanings of the practice that emerges from teacher experiences with a model for developing gamification activities, in the perspective of Continuing Education in use. The theoretical foundation used considered social interactionist principles, the theory of complex thought, cyberculture and the concepts related to competence development. This research used a qualitative approach based on a case study, whose subjects are teachers in a private teaching institution, working in the Early Years of Elementary Education. The instruments of data collection for this study were an online self-applied questionnaire, a selfreflective report and a semi-structured interview. The research findings show us that despite digital games being part of modern daily life, the research subjects only partially understood the concept of gamification. After the formative experiment, they showed a greater understanding of the concept and possible practical applications and, in particular, they could see the potential of this approximation between habits of leisure and habits of study.
\end{abstract}

KEYWORDS: Gamification. Teaching Practices. Elementary Education.

\footnotetext{
${ }^{1}$ Doutoranda em Educação - Pontifícia Universidade Católica do Rio Grande do Sul (PUCRS) - Porto Alegre, RS. Brasil. Analista de Tecnologia Educacional da Rede La Salle - Sociedade Porvir Científico. Associada à ANPED Associação Nacional de Pós-Graduação e Pesquisa em Educação. E-mail: cristina.martins@acad.pucrs.br ${ }^{2}$ Pós-Doutorado - Universidade do Texas (Austin). Doutora em Ciências da Computação - Universidade Federal do Rio Grande do Sul (UFRGS) - Porto Alegre, RS. Brasil. Professora Titular - Senior Lecture Computer Science School- FACIN/PUCRS - Pontifícia Universidade Católica do Rio Grande do Sul (PUCRS) - Porto Alegre, RS. Brasil. E-mail: giraffa@pucrs.br
}

Submetido em: 21/05/2016 - Aceito em: 22/10/2017 


\section{RESUMEN}

Este artículo presenta el resultado de una investigación sobre prácticas pedagógicas y gamificación, donde hemos discutido las posibilidades de resignificaciones de la práctica que emergen de las experiencias vividas por profesores con un modelo de desenvolvimiento de actividades gamificadas, en la perspectiva de la Educación Continua en el trabajo. La base teórica consideró los principios sociointeraccionistas, la teoría del pensamiento complejo, la cibercultura y las concepciones relacionadas al desenvolvimiento de competencias. La investigación de cuño cualitativo, de carácter exploratorio, se apoyó en un estudio de caso cuyos sujetos eran profesores de una institución privada, actuantes en los años iniciales de la Enseñanza Primaria (Educación básica). Los instrumentos de recolección de datos fueron: cuestionario online autoaplicable, relato autorreflexivo y entrevista semiestructurada. Los resultados de la investigación demostraron que, a pesar de que los games (juegos digitales) hagan parte de lo cotidiano de la actualidad, los sujetos comprendían parcialmente la concepción de gamificación. Luego de la vivencia con el experimento formativo, demostraron mayor entendimiento sobre el concepto y posibles aplicaciones prácticas y, especialmente, percibieron la potencialidad de la aproximación entre los hábitos de ocio y los hábitos de estudio.

PALABRAS CLAVE: Gamificación. Prácticas pedagógicas. Educación Básica.

\section{INTRODUÇÃO}

No cenário contemporâneo, permeado pela Cibercultura, caracterizada por Lévy (1999) como o espaço cultural interativo criado a partir da rede Internet e seus serviços, emergem diversas alternativas de se fazer Educação, as quais nos permitem ressignificações e questionamentos acerca das práticas pedagógicas relacionadas ao uso de Tecnologias Digitais de Informação e Comunicação (TD). Almeida e Pinto Neto (2015) destacam que os professores necessitam de tempo para fazer as devidas reflexões e incorporarem recursos tecnológicos que efetivamente Ihes auxiliem a criar práticas pedagógicas com seus estudantes, tendo por base as TD.

As práticas pedagógicas são ações que conduzem o professor, junto aos estudantes, a atuar nos processos de ensino e de aprendizagem. Entende-se que esses processos são interdependentes, sendo que um não se sobressai ao outro, ou seja, no momento em que o professor ensina, ele também aprende com o estudante, assim como, quando o estudante está aprendendo, está ao mesmo tempo ensinando o professor, numa relação recíproca e dialógica, uma via de mão dupla. Com isso, entendemos que essa relação entre estudantes e professores, por meio de processos de ensino e de aprendizagem, expressa-se nas práticas pedagógicas.

Compreende-se o docente como sujeito mediador, orientador e problematizador de situações de aprendizagens, planejando ações com intencionalidade e refletindo sobre elas. Contextualizar o que é cultural ao estudante nas suas vivências cotidianas faz parte da função socializadora da "escola"; portanto, é premente ao professor fazer o vínculo e o estabelecimento de relação de sentido às TD em suas práticas pedagógicas, a partir da sua reflexão-crítica. Entendemos que é na relação simbiótica entre aprender e ensinar que o conhecimento emerge, precisa ainda atrelar-se ao contexto sociocultural, permeado pelas interações e mediações advindas do outro e do ambiente (VIGOTSKY, 2007). 
Dentre as alternativas educacionais contextualizadas, a gamificação mostra-se como uma tendência promissora, que se define pela utilização de elementos de jogos digitais em atividades que, na sua origem, não são jogos. Gamificar uma atividade prática - em nosso contexto, uma prática pedagógica - não significa criar um jogo de viés pedagógico ou simplesmente jogar para ensinar. Vai além: é preciso compreender e significar mecânicas e dinâmicas presentes em jogos digitais permeando-os em práticas pedagógicas. E isso só se consegue por meio de vivências anteriores, a partir de elementos alinhados ao cotidiano da Cultura Digital.

Para avançarmos no entendimento da gamificação, faz-se necessário destacar concepções inerentes aos jogos nos processos de ensino e de aprendizagem, bem como suas interlocuções com as TD, percebendo seus limites e possibilidades. Primeiramente, destacamos um fator essencial nesse contexto: o desenvolvimento humano, que está diretamente imbricado com a aprendizagem. Para isso, situamo-nos em um referencial construtivista, de cunho sociointeracionista com base em Vygotsky (2007), considerando a interação social como o fio condutor do desenvolvimento humano. Logo, isso nos implica situar que compreendemos que esse desenvolvimento se dá na relação com o outro e/ou com o ambiente. Ou seja, o desenvolvimento humano está atrelado ao desenvolvimento cultural. Isso, ainda, leva-nos a afirmar que nosso referencial teórico-epistemológico direciona à compreensão de que aprendizagem, cultura, ensino e desenvolvimento não se opõem. Ou seja, não ignoramos suas vinculações, entendemos que estão integrados e se articulam por meio de complementaridades (SOLÉ; COLL, 2003).

Conforme os autores Lalueza, Crespo e Camps (2010), uma das "ferramentas" ${ }^{4}$ que vem sendo fortemente estudadas "[...] no que se refere ao seu impacto no desenvolvimento cognitivo, social e emocional é a dos videogames, provavelmente porque foi a primeira relacionada com os computadores que entrou na vida cotidiana de crianças e adolescentes". (p.51-52). Cabe ressaltar que há uma série de nomenclaturas que abarcam jogos que dependem de estruturas digitais, tais como: games, jogos eletrônicos, videogames etc. Aqui trataremos sempre o conceito como JOGOS DIGITAIS. Esses autores, baseados em seus estudos sobre as TD, ainda apontam que

[...] a prática dos videogames está relacionada com determinadas formas de processamento cognitivo. Processamento de grandes volumes de informação em tempo reduzido, atenção em paralelo, deslocamento de funções do texto para a imagem, ruptura da linearidade no acesso à informação, busca de retroalimentação imediata para corrigir ou modificar a ação. Tudo isso supõe algumas mudanças no que se refere ao tipo de inteligência promovida e valorizada

\footnotetext{
${ }^{4}$ Sempre que utilizarmos o termo "ferramentas", e seus análogos - instrumentos, objetos, recursos, artefatos etc. -, estamos nos embasando na concepção vigotskyana, ou seja, o indivíduo é mediado, desenvolve-se e aprende, também, pela apropriação e apreensão dessas ferramentas. "Assim, cada cultura se caracteriza por gerar contextos de atividade mediados por sistemas de ferramentas, os quais promovem práticas que supõem maneiras particulares de pensar e organizar a mente" (LALUEZA; CRESPO; CAMPS, 2010, p.51).
} 
pela escola. Não é um modelo oposto, mas é, em alguns aspectos, diferente ao do meio escolar, no qual pretende oferecer a informação escalonada, promove-se a atenção continuada e focalizada, o texto e a linguagem escrita têm prioridade acima de tudo e geralmente a retroalimentação é administrada a médio prazo". (LALUEZA; CRESPO; CAMPS, 2010, p.53)

Esse descompasso que os autores encontram entre os contextos escolar e extraescolar, também encontramos na formação inicial de professores, quando a realidade escolar parece ser traduzida de forma descolada do ambiente sociocultural contemporâneo (cibercultura).

Buscando avançar em estudos sobre práticas pedagógicas e gamificação, propomos discutir as possibilidades de ressignificações nas práticas pedagógicas que emergem das experiências vivenciadas por professores com a gamificação, na perspectiva da Educação Continuada em serviço. Com isso, temos o objetivo de problematizar práticas pedagógicas, desenvolvidas durante um experimento de formação continuada (oficina gamificada) com referência no modelo de atividades gamificadas proposto (MARTINS, 2015; MARTINS; GIRAFFA, 2016), apontando afastamentos e aproximações da concepção de gamificação e os possíveis indícios de ressignificações que emergiram desse processo formativo.

Essa pesquisa, de cunho qualitativo, é um estudo de caso, de caráter exploratório em que se investigou uma amostra de professores (sujeitos de pesquisa), de uma instituição de ensino privada, atuantes nos Anos Iniciais do Ensino Fundamental (Educação Básica). Os instrumentos de coleta de dados ao longo da pesquisa foram: questionário online autoaplicável, relato autoreflexivo e entrevista semiestruturada. Trata-se de desdobramentos de uma pesquisa de mestrado, que investigou como a constituição formativa dos professores implica o desenvolvimento de práticas pedagógicas a partir da gamificação, inserida em uma proposta de modelo de elementos de jogos digitais em atividades gamificadas (MARTINS, 2015).

Respeitando os devidos rigores relacionados à Ética na pesquisa, todos os instrumentos de pesquisa foram realizados mediante o consentimento dos sujeitos de pesquisa, por meio da disponibilização do Termo de Consentimento Livre e Esclarecido, bem como de seu aceite, o que antecedeu a coleta de dados.

\section{ASPECTOS TEÓRICOS RELACIONADOS À GAMIFICAÇÃO}

Huizinga (2012) caracteriza a ação lúdica (brincar, jogar, representar etc.) como um fator cultural da vida, uma forma específica de atividade, como função social. Para jogo, o autor traz a definição de "[...] uma atividade ou ocupação voluntária, exercida dentro de certos e determinados limites de tempo e espaço, segundo regras livremente consentidas, mas absolutamente obrigatórias, dotado de um fim em si mesmo, acompanhado de um sentimento de tensão e alegria" (HUIZINGA, 2012, p. 33). A cultura lúdica pensada pelo autor no século passado agora é fortemente mediada pelas TD, principalmente atreladas às

\begin{tabular}{|c|c|c|c|c|c|}
\hline (C) ETD- Educação Temática Digital & Campinas, SP & v.20 & n.1 & p. 5-26 & jan./mar.2018 \\
\hline
\end{tabular}


mídias sociais (ALVES, 2014). Tais tecnologias condicionam o contexto de cibercultura; "o prazer de ser desafiado para solucionar um problema e ser recompensado por isso, que é a essência da estrutura de um jogo, vem sendo levado para diferentes contextos objetivando engajar os sujeitos em distintas ações" (ALVES, 2014, p.103). Sato (2009) complementa dizendo que o jogo "[...] na cultura humana, está ligado à busca da diversão, do lazer e do desligamento das tarefas e responsabilidades do mundo cotidiano; é um objeto lúdico que leva o indivíduo à imersão" (p.37).

Destacamos aqui a definição de jogo digital proposta por Prensky (2012), que considera o jogo como um subconjunto de diversão e de brincadeiras, mas com uma estruturação que contém um ou mais elementos, tais como: regras, metas ou objetivos, resultado e feedback, conflito/competição/desafio/oposição, interação, representação ou enredo. Santaella e Feitoza (2009) completam a definição anterior dizendo que os jogos digitais são "construídos para suportes tecnológicos eletrônicos ou computacionais" (p. 10). As autoras, ainda, frisam a interdisciplinaridade evidente dos jogos digitais, por conta de seu caráter híbrido, que envolve desde a programação até técnicas psicológicas em sua constituição.

Portanto, entendemos que a gamificação pode ser considerada uma readaptação da cultura lúdica às técnicas condicionantes da cibercultura, um movimento natural imbricado ao desenvolvimento humano por meio da interação com o lúdico e com o ciberespaço. McGonigal (2011) foi uma das precursoras das teorizações da gamificação ao afirmar que promover o engajamento das pessoas em atividades cotidianas aplicando a lógica de jogos na vida real pode levar ao desenvolvimento de um mundo melhor. Kapp (2012) complementa afirmando que a gamificação contempla o uso de competências, mecânicas, estéticas e pensamentos dos jogos para engajar pessoas, motivar a ação, promover a aprendizagem e resolver problemas.

Dessa forma, para construção do modelo com intencionalidade educativa, tratamos a gamificação como uma estratégia que permite 0 desenvolvimento de práticas pedagógicas, a partir de elementos típicos de jogos digitais, podendo levar o docente à reflexão-crítica e à autorreflexão sobre sua atuação, bem como a ressignificá-la, considerando elementos socioculturais que condicionam nosso tempo histórico. Nesse sentido, entendemos que "[...] mudanças nas ferramentas culturais supõem mudanças nas formas de inteligência valorizadas pela sociedade e, portanto, na orientação do desenvolvimento cognitivo, social e emocional dos indivíduos". (LALUEZA; CRESPO; CAMPS, 2010, p.51). O professor é agente mediador entre estudante e sociedade. 
Entretanto, evidenciamos através de nossos estudos ${ }^{5}$ que a formação inicial de professores pouco tem considerado práticas pedagógicas permeadas pelas TD em seus currículos; logo, nem sempre se chega à reflexão-crítica, à autorreflexão e à ressignificação de práticas arraigadas da forma que esperamos dos professores em formação. Percebe-se um descolamento da realidade do estudante, imerso em um contexto sócio-históricocultural, com a realidade que a escola entende ser a do estudante. Logo, o professor muitas vezes pauta-se em práticas pedagógicas que desconsideram a complexidade inerente à cibercultura, sendo elas fragmentadas e descontextualizadas, pouco atendendo às necessidades de aprendizagem exigidas. Cabe ressaltar que se sabe das brechas socioeconômicas impostas pelas TD; entretanto, pesquisas vêm apontando para o aumento da inclusão digital. Em se tratando do Brasil, consideramos os dados apresentados pela pesquisa "TIC Kids Online Brasil 2014" 6 , a qual aponta que, aproximadamente, $82 \%$ de crianças e jovens brasileiros entre 9 e 17 anos possuem acesso a celular com internet.

O que autores como Prensky (2012) e Veen e Wraking (2009) nos trazem, em termos de reflexões para considerarmos nos processos pedagógicos, é a necessidade de compreensão dos hábitos que os estudantes têm fora da escola, da maneira como eles se comunicam, de como eles resolvem os seus problemas em redes, para trazer alguns desses hábitos para dentro da escola - porque fora da escola a cibercultura está estabelecida. Logo, precisa existir uma aproximação entre o que acontece no ambiente escolar e o que acontece fora da escola. A escola faz parte desse contexto.

Na cibercultura, houve mudanças quanto à concepção de o que é trabalho. Hoje, o que faz uma pessoa permanecer em uma atividade laboral não são somente aspectos financeiros, são também as oportunidades de crescimento e realização. Antigamente, trabalhava-se primeiro, aposentava-se, depois desfrutava-se a vida. Atualmente, essa geração quer desfrutar a vida enquanto trabalha. Isso é uma mudança paradigmática que tem que ser considerada pela escola. Outro aspecto são os jogos, que retornam com força aos hábitos sociais cotidianos, influenciados pelos dispositivos móveis que revolucionaram a forma como as pessoas se comunicam, resolvem seus problemas cotidianos e também se divertem. Comumente, vê-se, em filas de ônibus, bancos, supermercados, shoppings e outros espaços, pessoas usando seus celulares para acessarem notícias, conversarem com amigos e jogarem.

Esse é um dos motivos pelo qual a gamificação retorna à pauta das possibilidades educacionais, adotando aproximações relevantes e com potencial pedagógico dos comportamentos dos estudantes relacionados aos jogos digitais. O mote principal da gamificação seria auxiliar na motivação do estudante a aprender e construir seu

\footnotetext{
${ }^{5}$ Em Martins (2015) apresentamos dados que apontam para tal evidência.

${ }^{6}$ http://www.cetic.br/pesquisa/kids-online
} 
conhecimento. Considerando os princípios construtivistas, de cunho sociointeracionista, a motivação e a interação social com os outros e com o meio cultural constituem fatores prementes para a aprendizagem.

Thiebes et al. (2014) realizaram uma revisão de literatura acerca dos elementos de jogos digitais usados na perspectiva da gamificação. Os autores classificam esses elementos como mecânicas e dinâmicas de jogos digitais. As mecânicas são características funcionais dos jogos digitais e proporcionam variadas ações, comportamentos e mecanismos de controle, permitindo a interação. As dinâmicas motivam as reações do sujeito, ou seja, como ele responde a determinada mecânica do jogo digital, no contexto da atividade gamificada. Essa abordagem é apoiada no trabalho de Deterding et al. (2011). Deterding e seus colegas foram os primeiros a propor tal divisão e entendimento da dinâmica, e Kapp (2012) traz uma classificação similar.

Dentre os elementos de jogos digitais, consideramos significativos no contexto educacional aqueles que, desenvolvidos em atividades gamificadas, possam aprimorar competências relevantes ao estudante em seu tempo histórico, tais como: colaboração, cooperação, reflexão (pensamento crítico), autonomia, domínio de conteúdo, hábitos de estudo, limites, etc. Competências que auxiliem no desenvolvimento da fluência digital e permitam formar cidadãos adaptados e articulados ao contexto sociocultural em que vivemos.

Logo, consideramos como elementos de jogos digitais adequados para serem desenvolvidos nas práticas pedagógicas: Missão, Enredo, Níveis/Desafios, Objetivos Específicos, Recursos, Colaboração, Help, Itens, Desempenho, XP (Experience Points, ou seja, nível de experiência associado ao processo de aprendizagem), Pontuação e Avatar. $\mathrm{Na}$ tabela 1 , descrevemos esses elementos de jogos digitais e traçamos a relação entre eles na figura 1. A figura 1 também se configura como uma proposta de modelo de elementos de jogos digitais em atividades gamificadas (MARTINS; GIRAFFA, 2015). 
TABELA 1 - Codificação das unidades de sentido

\begin{tabular}{cl} 
ELEMENTO & \multicolumn{1}{c}{ DEFINIÇÃO } \\
\hline Missão & $\begin{array}{l}\text { Se configura como a meta apresentada para justificar a realização da atividade } \\
\text { como um todo. É ampla e está diretamente relacionada ao enredo. A conclusão de } \\
\text { todos os níveis/desafios leva ao fim da atividade ou "zerar a atividade". }\end{array}$ \\
\hline Enredo & $\begin{array}{l}\text { É a representação de um cenário ou contexto por meio de elementos narrativos e } \\
\text { imaginativos. Caracteriza à atividade um ambiente de jogo e define o avatar do } \\
\text { estudante. Além disso, serve de pano de fundo para a missão. }\end{array}$ \\
\hline Avatar & $\begin{array}{l}\text { Vai além do personagem que é incorporado a partir de um perfil definido. O avatar } \\
\text { é a representação virtual (digital ou não) do estudante. }\end{array}$ \\
\hline Níveis/ & $\begin{array}{l}\text { São as etapas determinadas pelos objetivos específicos. Ao atingi-los se avança a } \\
\text { uma nova etapa. Podem ser dados por um NPC (non-player character ou } \\
\text { personagem não jogável) e, ao completá-los, o estudante ganha XP, itens e/ou } \\
\text { pontos, avançando em seu desempenho. }\end{array}$ \\
\hline $\begin{array}{l}\text { Objetivos } \\
\text { específicos }\end{array}$ & $\begin{array}{l}\text { Direcionam o jogo, sendo pontuais e claros. São orientados por regras, } \\
\text { complexificando seu alcance. São passíveis de serem concluídos, conforme o } \\
\text { término dos níveis/desafios. }\end{array}$
\end{tabular}

São os auxílios recebidos pelo estudante ao longo da realização da missão; podem

Recursos vir de pessoas ou de ferramentas. Assim, constituem-se nas ajudas (online ou não), na colaboração de outros sujeitos, nos tutoriais explicativos em forma de Help e nos recursos que permitem aquisição de itens.

\begin{tabular}{cl}
\hline Colaboração & $\begin{array}{l}\text { Acontece por meio da interação entre sujeitos em rede de maneira online ou física } \\
\text { através de grupos ou equipes. }\end{array}$ \\
\hline Help & $\begin{array}{l}\text { São os tutoriais explicativos que auxiliam na compreensão da missão e dos } \\
\text { níveis/desafios. }\end{array}$ \\
\hline Itens & $\begin{array}{l}\text { São os bônus, ou as habilidades específicas, conferidos aos personagens durantes as } \\
\text { etapas percorridas de acordo com o desempenho obtido. }\end{array}$ \\
\hline Desempenho & $\begin{array}{l}\text { Constitui-se nos resultados quantitativos e qualitativos das aprendizagens } \\
\text { alcançadas ao longo das etapas atreladas dos níveis/desafios. Considera todo o } \\
\text { processo de ensino e aprendizagem desenvolvido na resolução da missão. }\end{array}$ \\
\hline XP & $\begin{array}{l}\text { Nível de experiência desenvolvido ao longo do processo, ou seja, corresponde ao } \\
\text { desempenho do estudante em termos de resultados qualitativos. Esse processo de } \\
\text { aprendizagem, atrelado ao desenvolvimento de competências e habilidades pelo } \\
\text { estudante, por meio das experiências vivenciadas ao longo da atividade gamificada } \\
\text { é o mais relevante para avaliação do estudante. }\end{array}$ \\
\hline Pontuação & $\begin{array}{l}\text { Resultado quantificado por meio de pontos. Está diretamente relacionado ao } \\
\text { desempenho quantitativo e aos itens recebidos pelo estudante. Essa quantificação } \\
\text { também faz parte da avaliação do estudante, mas se põe em segundo plano. Faz-se } \\
\text { necessária devido à cultura da perfomatividade, que impõe ao ecossistema escolar } \\
\text { mensurar a aprendizagem dos estudantes com sistemas de representação de notas. }\end{array}$
\end{tabular}

Fonte: MARTINS, 2015. 
Um arcabouço é uma referência que necessita ser adaptada ao contexto que será inserido. Logo, existem elementos extramodelo a serem considerados nesse processo, como no caso da organização/adoção de uma estratégia pedagógica em uma instituição de Educação Básica, por exemplo, onde articulamos o modelo com base nas políticas que orientam a organização curricular e possuem como respaldo as Diretrizes Curriculares Nacionais para a Educação Básica (BRASIL, 2013). As referências conceituais e procedimentais desse documento pautam-se, principalmente, na Constituição Federal, Estatuto da Criança e do Adolescente, Lei de Diretrizes e Bases da Educação Nacional, bem como em documentos internacionais orientadores produzidos pela ONU, UNICEF, UNESCO, entre outros.

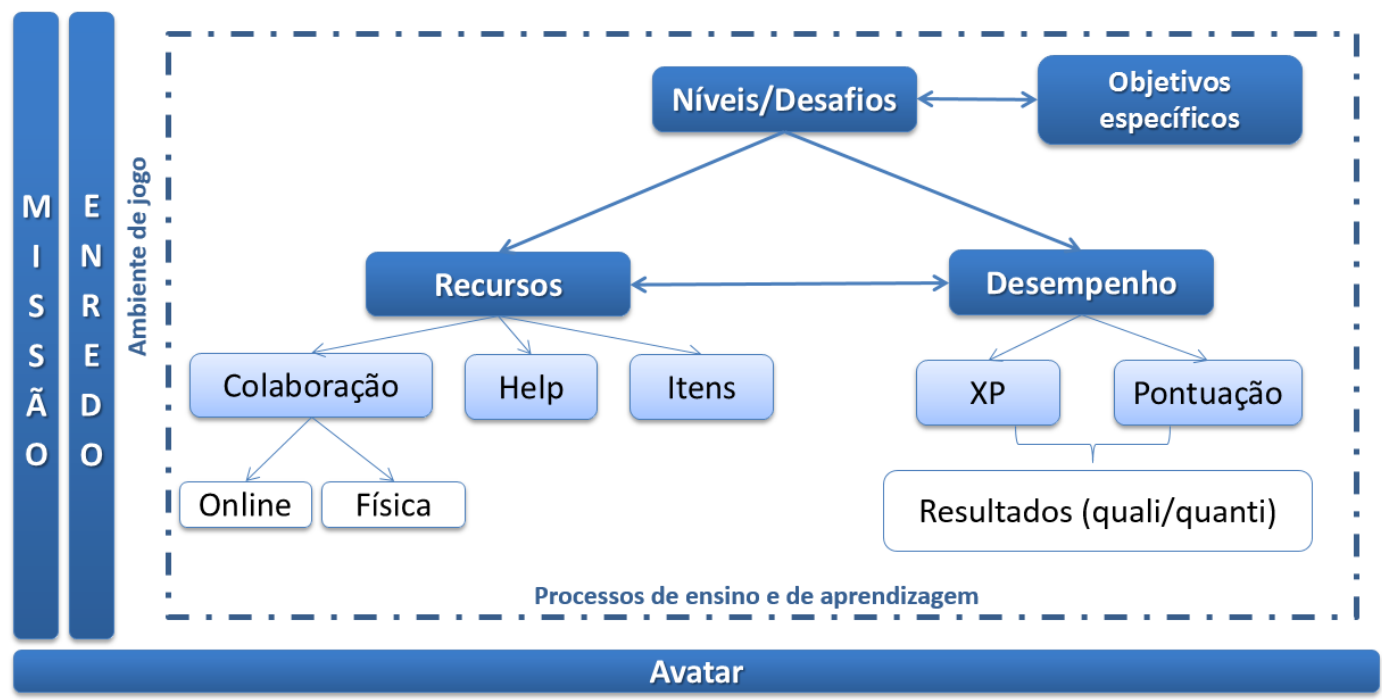

FIGURA 1 - Modelo de elementos de jogos digitais em atividades gamificadas. Fonte: MARTINS, 2015.

Entendemos que esse enfoque pode ser articulado pelo modelo proposto, inclusive rompendo com barreiras disciplinares, articulando de forma interdisciplinar a prática pedagógica. Nesse sentido, Morin, Almeida e Carvalho (2013) contribuem afirmando que "[...] é primordial aprender a contextualizar e melhor que isso, a globalizar, isto é, a saber situar um conhecimento num conjunto organizado" (p.59). Assim, pode-se conduzir o professor a ressignificar suas práticas já constituídas, por meio do incentivo à reflexãocrítica e autorreflexão sobre sua própria atuação. Ou seja, possíveis desconstruções de crenças, de representações e de certezas já consolidadas acerca da prática do professor, uma vez que em grande parte somos oriundos do ensino tradicional, que apresenta esses saberes de forma fragmentada e descontextualizada. 
Santaella (2013) corrobora nossa compreensão acerca desse arcabouço quando afirma que os jogos digitais, devido a sua plasticidade, ou melhor, características transmidiáticas ${ }^{7}$, favorecem distintas adaptações, traduções e misturas, sendo a gamificação inerente à ubiquidade dos jogos digitais. Então, justifica, na cibercultura, a necessidade de releituras das práticas pedagógicas que já vêm sendo executadas, não só no sentido da transposição metodológica, mas sim de ressignificação, como já destacado. Ou seja, não basta inserir elementos de jogos digitais em práticas antigas; é preciso autorrefleti-las e, a partir disso, constituir novas práticas com novas articulações imbricadas aos elementos desses jogos e dos diversos conhecimentos que necessitam ser trabalhados com determinado grupo. E isto não se consegue de maneira rápida ou em curto espaço de tempo.

A fragmentação e a descontextualização da formação se reflete na dificuldade do docente em organizar atividades interdisciplinares, quer seja dentro do seu domínio de conhecimento, quer seja na interlocução entre saberes de diversas áreas, bem como no aplicar elementos da cibercultura. Essas últimas são mais difíceis de serem organizadas e realizadas em face da falta do hábito de estudar e aprender tecendo inter-relações, ou seja, montar o conhecimento em rede, como requer a resolução de problemas complexos típicos da cibercultura.

\section{PROCEDIMENTOS METODOLÓGICOS DA PESQUISA}

Esta pesquisa de abordagem qualitativa se desenvolveu por meio de um estudo de caso, de caráter exploratório. Os sujeitos de pesquisa foram 21 professores, de uma instituição de ensino privada, atuantes nos Anos Iniciais do Ensino Fundamental (Educação Básica). Como instrumentos de coleta de dados, tivemos:

(a) questionário online autoaplicável para diagnóstico, composto por 13 perguntas fechadas e de múltipla escolha, mais 2 perguntas abertas de caráter opinativo, enviada aos 21 sujeitos da pesquisa. Foi alcançado $100 \%$ de retorno da amostragem intencional à qual o instrumento foi enviado;

(b) relato autorreflexivo posterior à aplicação do experimento na perspectiva da Educação Continuada em serviço, que se caracterizou por uma pergunta aberta disponibilizada aos 21 sujeitos da pesquisa, onde estes avaliaram por escrito o experimento, manifestando sua opinião, seu envolvimento, sua participação e suas aprendizagens construídas. Obtivemos $100 \%$ de retorno da amostragem; e

\footnotetext{
7 Santaella (2013) considera que um jogo digital pode ser uma transmídia, pois abarca diferentes mídias e hipermídias pré-existentes, assim como é fluído entre elas, ou seja, pode converter-se em outros formatos. Um exemplo clássico de jogo digital transmídia é Lara Croft - Tomb Raider, que teve filmes baseados na narrativa do jogo digital.
} 
(c) entrevista semiestruturada, composta por 10 perguntas abertas, aplicado à dois sujeitos selecionados que praticaram com suas estudantes atividades gamificadas.

Para traçar o perfil dos sujeitos de pesquisa, utilizamos os dados coletados com o Questionário online autoaplicável, que foi respondido por 21 professores e/ou gestores dos Anos Iniciais do Ensino Fundamental. Dos 21 sujeitos de pesquisa, 85,7\% eram do sexo feminino e $14,3 \%$, do sexo masculino. Em relação à faixa etária, a maioria dos sujeitos de pesquisa tinham entre 30 e 39 anos, o que corresponde a 47,6\% dos respondentes, já $23,8 \%$ tinham entre 40 e 49 anos, 13,3\% entre 20 e 29 anos, 9,5\% entre 50 e 59 anos e 4,8\%, mais que 60 anos, o que corresponde a 1 sujeito de pesquisa. Não houve sujeitos de pesquisa com faixa etária inferior a 20 anos. No gráfico 1, esses números são evidenciados. Sobre experiências anteriores com jogos, todos os sujeitos de pesquisa afirmaram ter alguma vivência anterior ao experimento.

O experimento de formação continuada foi denominado "Ciclo de formação docente" e foi organizado em três momentos:

a) Momento 1: Foi realizada uma palestra (apresentação oral) de 1 hora sobre a temática "Gamificação na Educação: conceito, limites e possibilidades" aos professores, em que realizamos uma explanação sobre conceitos teóricos relacionados à gamificação. Assim, buscamos mobilizar saberes teóricos acerca da gamificação através do enfoque conceitual com os sujeitos de pesquisa;

b) Momento 2: Desenvolvemos uma oficina, ou seja, uma reunião do grupo com duração de 3 horas em que foram demonstrados e aplicados na prática atividades gamificadas a partir do modelo proposto. A oficina foi chamada de "Design de práticas pedagógicas incluindo elementos de jogos digitais em atividades gamificadas". Desta forma, propomos aos professores experienciar na prática, por meio de conteúdos procedimental e atitudinal, competências inerentes à complexidade de gamificar. Os sujeitos de pesquisa tiveram a oportunidade de criar atividades pedagógicas gamificadas e posteriormente aplicar com seus estudantes.

c) Momento 3: Para fechamento do ciclo formativo foi feito um Seminário integrador "Partilhando Experiências", com objetivo de que os professores compartilhassem as práticas pedagógicas gamificadas que foram criadas a partir da oficina. Com isso propiciamos uma troca das experiências vivenciadas ao gamificar uma atividade pedagógica, por meio da partilha coletiva (oral) de saberes.

Com a análise dos dados coletados, emergiram resultados consistentes que nos permitem fazer este desdobramento, extrapolando os resultados da dissertação, problematizando a representação da gamificação dos professores antes e após o desenvolvimento do experimento. Assim, foi possível apontar aproximações e afastamentos 
do conceito da gamificação e os possíveis indícios de ressignificações nas práticas pedagógicas que emergiram desse processo formativo.

Para realizar essa análise dos dados, utilizamos a Análise Textual Discursiva (ATD). Esse método é descrito por Moraes e Galiazzi (2011, p. 7) como "[...] uma metodologia de análise de dados e informações de natureza qualitativa com a finalidade de produzir novas compreensões acerca os fenômenos e discursos". Para aplicação do método, deve-se partir de materiais textuais como corpus de análise e quatro fases devem ser percorridas, as quais consistem na desmontagem de textos, no estabelecimento de relações, no captar o novo emergente e, por fim, num processo de auto-organização dos dados que leva à construção das categorias, construindo novas compreensões que irão emergir do processo.

Seguindo as etapas para operacionalização da ATD, iniciamos pela desmontagem dos textos, que se caracteriza como processo de unitarização, no qual fragmentamos o corpus de análise, atingindo as unidades de sentido (MORAES; GALIAZZI, 2011). Para isso, codificamo-las, conforme tabela 2.

TABELA 2 - Codificação das unidades de sentido

\begin{tabular}{cc}
\hline CóDIGOS & DESCRIÇÃo \\
\hline $\mathbf{X}$ & Codificação do instrumento: questionário (Q), experimento Ciclo de Formação \\
Docente (F) ou Entrevista (E).
\end{tabular}

Fonte: As Autoras (2016).

Após, procedemos com a reescrita das unidades de sentido, para assumirem um significado mais completo. Por fim, atribuímos uma palavra-chave para cada unidade produzida, a partir de quando emergiram conceitos que deram origem às categorias. Assim, foram estabelecidas as relações entre essas palavras, reunindo conjuntos de elementos de significação próximos, ou seja, o processo de categorização.

A partir dos desdobramentos da dissertação, apresentamos duas categorias emergentes: "Afastamentos e aproximações da concepção de gamificação" e "Os indícios de ressignificações emergentes da gamificação nas práticas pedagógicas". 


\section{OS ACHADOS DA PESQUISA}

Consideramos como pano de fundo da análise nosso referencial teórico epistemológico, situado nos princípios construtivistas, de cunho sociointeracionista (VIGOTSKY, 2007), por meio dos quais compreendemos o professor como agente mediador do estudante e da sociedade. Logo, suas estratégias de ensino são um dos principais meios de execução dessa mediação, num cenário de interação social. Ou seja, essa mediação estudante $X$ sociedade se dá, principalmente, por meio das práticas pedagógicas interdisciplinares e contextualizadas em um tempo histórico.

Para evidenciarmos ao longo do estudo possíveis indícios de ressignificações de práticas pedagógicas já consolidadas, decorrentes de uma formação inicial fragilizada, que pouco dialoga com o contexto sociocultural, primeiramente problematizamos as representações dos sujeitos de pesquisa sobre a concepção de gamificação, que, em nosso entendimento, é inerente ao nosso tempo sócio-histórico, uma vez que é uma readaptação do lúdico às ferramentas emergentes da cibercultura. Para isso, delineamos as categorias de análise: "Afastamentos e aproximações da concepção de gamificação" e "Os indícios de ressignificações emergentes da gamificação nas práticas pedagógicas".

\section{Afastamentos e aproximações da concepção de gamificação}

Nesta categoria de análise, apresentamos interlocuções empíricas explicitadas antes da realização do experimento com o ciclo de formação docente, coletadas através do questionário online autoaplicável, de caráter diagnóstico, onde os sujeitos de pesquisa descreveram práticas pedagógicas em que aplicaram elementos de jogos e que consideravam de maior sucesso.

Por ocasião de descrever práticas pedagógicas que desenvolveram usando elementos de jogos, alguns sujeitos de pesquisa demostraram compreender a gamificação como a criação de jogos, entendendo que o uso de elementos de jogos digitais é o mesmo que produzir um jogo, seja pelo próprio professor, seja por seus estudantes. As interlocuções empíricas ${ }^{8}$ que seguem nos levam a essa reflexão:

"Classificação com número e quantidade com tampinhas de garrafa pet (Jogo de contagem). Compreensão de valores na resolução de problemas matemáticos". QP6S1

"Criação de jogos de tabuleiro envolvendo expressões numéricas, criação de uma "lojinha" envolvendo sistema monetário, bingo, jogos em equipes sobre tabuada...Jogos online envolvendo ortografia, sistema solar, ar água e solo". QP6S2

"O jogo com a bola colorida e os envelopes também da mesma cor. Pode ser utilizado com vários a associação de cores, números, música e conteúdo visto em aula". QP6S3

\footnotetext{
${ }^{8}$ Todos os extratos de escrita dos sujeitos de pesquisa foram transcritos Ipsis litteris do corpus de análise.
}

v.20 n.1

p. $5-26$ jan./mar.2018 
Verificamos, também, que alguns sujeitos de pesquisa deram fortes indícios de que sua concepção de gamificação seria uso de jogos, ou seja, jogar:

\author{
"Jogos de adivinhação tipo "Qual é a música?"”. QP6S4 \\ "Jogos envolvendo raciocínios lógicos". QP6S5 \\ "Jogo de dados com material dourado, memória de sílabas, trilha usando fórmulas \\ matemáticas. Jogos envolvendo unidade, dezena e centena". QP6S6
}

Cabe ressaltar que a gamificação não significa jogar, nem criar jogos, mas sim como afirma Kapp (2012), contemplar o uso de competências, mecânicas, estéticas e pensamentos dos jogos em atividades para engajar pessoas, motivar a ação, promover a aprendizagem e resolver problemas. Destacamos que práticas gamificadas devem ser desenvolvidas criteriosamente usando todos os elementos dos jogos digitais que forem apropriados ao contexto escolar, não apenas elementos que remetam a pontuação e recompensas, o que justifica a criação do nosso modelo de atividade gamificada, onde fizemos uma seleção de elementos para gamificar.

Neste momento da análise, vemos expresso constantemente nas interlocuções dos sujeitos de pesquisa a aplicação de elementos de jogos, principalmente pontuação e recompensas, os quais favorecem e reforçam práticas pedagógicas com viés tradicional, pouco percebemos características sociointeracionistas nos elementos citados, o que não era nossa. Cabe ressaltar que antes do ciclo formativo docente, a maioria dos sujeitos não possuíam contato com a gamificação conforme propomos neste estudo, o que justifica o distanciamento entre nossa expectativa e o que os professores expressavam sobre a concepção. Ao longo da análise poderemos demostrar as mudanças em suas representações sobre a gamificação:

"Fizemos três equipes, e fomos para o pátio fazer a brincadeira da corrida com a colher. (Teve o 1ํ, 2으, 3 lugar), a partir disto dei a matéria nova, que era números ordinais". QP6S7

"Gincana do conhecimento - A turma é dividida em grupos, diariamente, e cada grupo tem uma identidade. No dia da gincana, cada grupo recebe um desafio inicial, relacionado aos conhecimentos trabalhados. O grupo deve resolver o problema e quando todos conseguem aplicar, a equipe bate o sino, gerando pontos para a sua equipe. Ao bater o sino, o grupo inicia a outra fase (pega o próximo desafio)". QP6S8

Destacamos, também, que por meio de atividades gamificadas espera-se desenvolver competências necessárias a um contexto de cibercultura tal como a fluência digital e o pensamento crítico. Para isso, é preciso uma interlocução com nosso tempo histórico (MARTINS, 2015), pois a fluência digital diz respeito à naturalidade em articular a linguagem digital (formas digitais de comunicação) e adaptar-se a ela. O pensamento crítico sobre as TD aporta o uso crítico-reflexivo do ciberespaço pelo estudante, promovendo uma educação emancipatória e cidadã. Condicionar estudantes a buscar resultados quantificados 
e a competir já não é suficiente; buscamos ir além dessas práticas tradicionais, por vezes alienantes. Santaella diz que

[...] a tecnologia computacional está fazendo a mediação das nossas relações sociais, de nossa autoidentidade e do sentido mais amplo da vida social. O celular com mais ou menos inteligência e várias outras formas eletrônicas de extensão humana tornaram-se essenciais à vida social e se constituem nas condições para a existência da cibercultura. (2013, p. 235)

Num relato realizado pelo sujeito 9 , ao responder à pergunta dissertativa 9 do questionário online autoaplicável, por ocasião da sua participação anterior em uma formação de professores sobre gamificação, conseguimos perceber aproximações do que seria uma atividade gamificada, conforme nossa definição:

\footnotetext{
"Na capacitação de professores montei um mosaico com imagens e conceitos sobre o processo de aprendizagem de alunos e práticas docentes. Sempre divido o grupo em equipes para montarem este mosaico conforme o entendimento de cada grupo. Após a conclusão os grupos apresentam qual foi a lógica que utilizaram para montar o mosaico. Por último faço o fechamento dizendo que todos atingiram o objetivo, porém por vários caminhos. Os grupos gostam bastante, pois aprendem sobre metodologias ativas e o processo de construção do saber apenas lendo as imagens, palavras e estabelecendo relações entre elas". QP6S9
}

Nessa atividade proposta, verificamos que o sujeito buscou trabalhar competências relevantes em processos gamificados, tais como: colaboração, pensamento crítico, autonomia, protagonismo, autoria, etc. Além disso, trouxe elementos de jogos digitais significativos para práticas pedagógicas, como, por exemplo: desafios, descobertas, empoderamento em grupo, uso de recursos diversificados e XP. Logo, há indícios de gamificação nesse exemplo, que se aproxima do modelo que propomos, uma vez que tem a intenção de aprimorar competências relevantes ao estudante, articuladas ao contexto sociocultural em que vivemos.

Finalmente, concluímos que, em relação aos afastamentos da concepção de gamificação, existem três situações: gamificação como sinônimo de criação de jogos, gamificação igual a jogar e uso de elementos de jogos digitais como transposição didática em práticas pedagógicas tradicionais. Entretanto, existem aproximações, tais como: a intenção de desenvolver ou aprimorar competências necessárias à cibercultura. Essas evidências justificaram a proposição de um experimento de formação continuada.

Os indícios de ressignificações emergentes da gamificação nas práticas pedagógicas.

Após a realização desse experimento, buscamos indícios de que ressignificações das práticas pedagógicas ocorreram, pois era nosso objetivo provocar reconstruções no fazer docente dos sujeitos de pesquisa. Assim, descrevemos essa categoria de análise, buscando tais indícios por meio de relatos que demostraram a ocorrência da articulação do pensamento complexo relacionado ao gamificar uma atividade pedagógica, uma vez que consideramos este processo como uma forma de ressignificar ações já produzidas por um

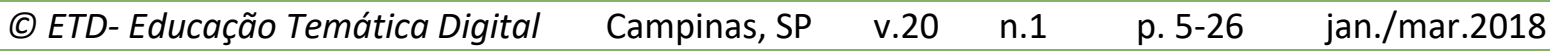


sujeito. Inserir o modelo proposto em práticas pedagógicas pressupõe essa articulação e mobilização de saberes docentes. "O problema crucial de nosso tempo é o da necessidade de um pensamento apto a enfrentar o desafio da complexidade do real, isto é, de perceber as ligações, interações mútuas, os fenômenos multidimensionais, as realidades que são, simultaneamente, solidárias e conflituosas [...]" (MORIN; ALMEIDA; CARVALHO, 2013, p.7677).

As interlocuções empíricas apresentadas a seguir demonstram reflexões-críticas e autorreflexões com possíveis indícios de ressignificações acerca de práticas pedagógicas já consolidadas:

"Usamos em sala de aula [elementos de jogos digitais] mais como uma técnica de incentivação a como um complemento lúdico." FR1S1

"O termo desconhecido surpreendeu ao apresentar elementos já utilizados no cotidiano. Porém, é importante ressaltar que, como formadores de opiniões, o professor precisa ter claro a intencionalidade nas suas atividades." FR1S2

"Eu tinha uma ideia errônea sobre gamificação. Hoje tenho uma compreensão melhor e percebo que em alguns momentos eu fazia essa junção entre conhecimentos, habilidades, games, vida do aluno..." FR1S3

Os sujeitos de pesquisa quando questionados acerca do desafio de aplicar um modelo para desenvolver uma atividade gamificada demonstraram ter concepções diferenciadas quanto ao uso de jogos. Por exemplo, o sujeito 1 respondente da entrevista, indicou a pontuação como um desafio, pois já utilizava informalmente elementos de jogos digitais; resultados quantitativos não eram seu foco.

"A pontuação foi o mais desafiador. Eu nunca tinha pensado em fazer dessa forma, né? [...] Então a gente tá aprimorando agora com a questão da pontuação, agora nós vamos começar a trabalhar folclore. Até botei no meu planejamento, assim né a questão dá: O que é? O que é? Enfim, de trabalhar com um tipo de gincana, assim, né?" ES1

Isto de certa forma vai de encontro às indicações do questionário online autoaplicável, quando se indagou sobre quais eram os elementos de jogos digitais considerados nas práticas pedagógicas dos sujeitos de pesquisa naquele momento. Os resultados são explicitados na figura 2. Pode-se perceber que 9 sujeitos de pesquisa indicam que a pontuação é considerada em suas práticas pedagógicas, que julgam ser atividades gamificadas, totalizando $42 \%$ dos sujeitos de pesquisa, o que corresponde a quase metade dos professores. 


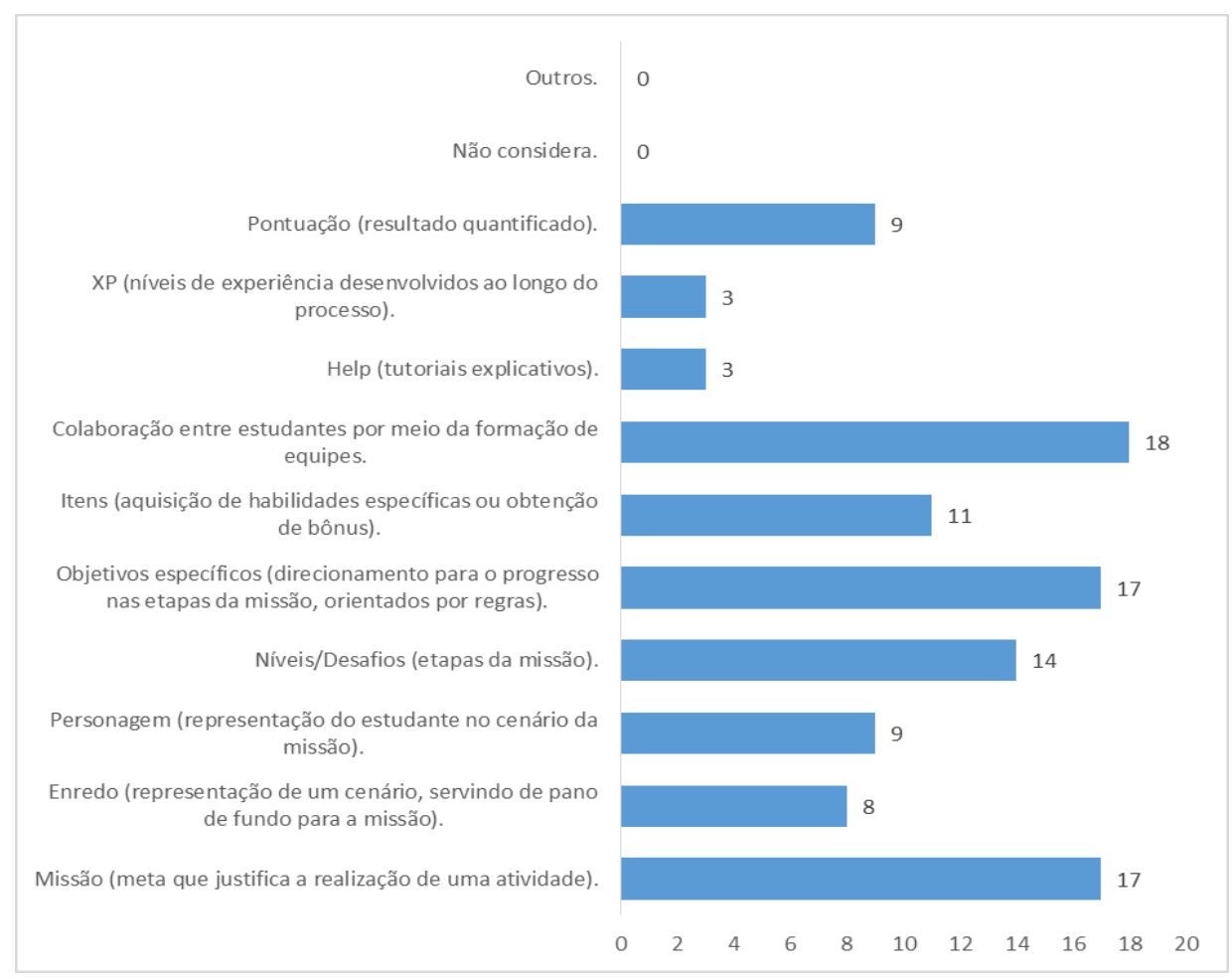

FIGURA 2 - Elementos de jogos digitais considerados nas práticas pedagógicas Fonte: MARTINS, 2015.

Além disso, os sujeitos de pesquisa trouxeram implícito em suas falas o desafio de planejar e ter uma intencionalidade como pano de fundo de sua atividade pedagógica, o que dialoga com o apontamento de Santaella (2013):

[...] para serem utilizados com fins educacionais, os jogos precisam possuir objetivos de aprendizagem bem definidos, ensinar conteúdos das áreas de conhecimentos visadas ou promover o desenvolvimento de competências para ampliar a capacidade cognitiva e intelectual dos estudantes. (2013, p. 257)

Ainda, constatou-se que os cursos de Formação Inicial nem sempre trabalham a ação pedagógica como um ato cheio de intencionalidade, e que o planejamento é fundamental. Esses são traços fundamentais de princípios construtivistas, de cunho sociointeracionista. Como é possível atuar na zona de desenvolvimento proximal dos estudantes sem planejar, aplicar, refletir criticamente, autorrefletir e avaliar as próprias práticas pedagógicas? Sabemos que a prática pedagógica é intencional; mesmo quando não se tem claro o referencial teórico epistemológico, há teorias operando. Logo, emerge o currículo oculto por trás das práticas pedagógicas. 
"O fato de fazer quando a gente executou os passos, quando a gente tava fazendo, acho que a gente não faz tão organizado. Porque foi tudo um passo a passo, bem descrito, bem organizado, qual eram os objetivos daquele jogo, o personagem, recursos, o que a gente ia precisar. Quando a gente tá construindo a gente vai lá e pensa para aquela tua turma, aquele modelo e faz o que precisa ser feito. Então acho que trouxe o desafio, mas também foi o mais prático quando a gente teve que executar é o que a gente faz, mas mais organizado, mais minucioso". ES2

Quando se tem um arcabouço, ou modelo, os professores, principalmente, que apresentam grande vivência de sala de aula, por mais fragmentada e descontextualizada que seja sua formação no que diz respeito ao incentivo da constituição de práticas pedagógicas a partir das TD, de algum modo e em algum grau, fazem-no implicitamente e de forma intuitiva. O que não é diferente no caso da gamificação, em que elementos de jogos digitais são utilizados nas práticas pedagógicas, mas de forma isolada, não como proposto no modelo, de maneira formalizada e intencional. Kapp (2012) destacou que um único elemento de jogo digital ou até mesmo um ou dois elementos por si só não constituem um ambiente de aprendizagem envolvente e imersivo. É a inter-relação dos elementos que torna a gamificação envolvente. Alves (2014) também compactua com essa ideia.

Esses elementos de jogos digitais propostos pelo modelo de forma sutil estavam presentes na Educação Infantil e, principalmente, em nosso campo empírico, Anos Iniciais do Ensino Fundamental. Essa investigação trouxe dados indicadores de que, ao trabalhar a gamificação, é possível contribuir para a ressignificações às práticas pedagógicas a partir de TD, que são inerentes ao contexto sociocultural.

Os sujeitos de pesquisa já inseriam elementos de jogos digitais de forma isolada em suas práticas pedagógicas, mas desconheciam a formalização de conceitos. Esse "dar-se conta" da formalização de uma prática pedagógica é mais um indício de que ressignificações ocorreram e a autorreflexão foi um processo presente a alguns sujeitos de pesquisa, e nos aponta para um pequeno avanço com esse grupo. Quando se constrói uma estrutura para gamificar e se desenvolve um postulado de gamificação, estão se reunindo todos os elementos que eram utilizados de forma fragmentada e se está tencionando conduzir a uma reflexão da prática pedagógica construída de forma intuitiva e fragmentada, ou seja, refletir sobre a gamificação pode levar a possíveis ressignificações de práticas pedagógicas.

Por fim, a experiência do ciclo formativo foi significativa para os sujeitos entrevistados, de forma a conduzi-los a reflexões críticas e autorreflexões aprofundadas. Nesses casos, há indícios de que foram refletidas práticas pedagógicas e de que saberes foram mobilizados para aprimoramentos dos processos de ensino e de aprendizagem. Entretanto, entendemos que, para que esse processo ocorra, os sujeitos de pesquisa precisam estar abertos para receber a formação. Sabemos que nem todos os sujeitos de pesquisa chegaram ao nível de reflexão dos sujeitos selecionados, que aplicaram atividades 
gamificadas baseadas no modelo proposto. Seguem interlocuções empíricas que demostram a constituição de outras práticas pedagógicas, aparentemente com maior intencionalidade usando elementos de jogos digitais:

\begin{abstract}
"Até nós usamos na quarta [repetição da experiência], na sexta eu fiz outro jogo com eles, mas, ai eram cartas que eles tinham que ir abrindo e cada carta tinha um conteúdo que tinha sido trabalhado de alguma forma, uma era jogo de memória, era uma cruzadinha, um caçapalavras, eles tinham que montar um relógio. Então foram alguns desafios, mas, já mais voltados para o nosso conteúdo de sala de aula". E1S2
\end{abstract}

Agora o que ficou combinado é que pelo, como ficou muito legal os trabalhos, que esses outros trabalhos ainda serão aplicados, não sei se ainda nesse semestre ou no início do ano, mas que a gente ainda quer fazer a aplicação daqueles trabalhos. E2S3

A formação, na perspectiva de Educação Continuada em serviço e de curta duração, pode auxiliar, mas não facilmente, a preencher as lacunas deixadas pela formação docente inicial desarticulada da realidade atual. Processos de formação continuada de forma extencionista de curta duração podem promover reflexão e iniciar um processo que vem na sequência da necessidade de fazer efetivamente a continuidade, não sendo uma educação pontual. Percebemos que a Educação Continuada também precisa ser refletida, pois, usualmente, propõe-se e entende-se como um momento autocontido, desvinculado das fragilidades que se percebem em grupos docentes.

\title{
5 ENCAMINHANDO À FINALIZAÇÃO DO TEXTO...
}

Propusemos com este estudo avançar nas discussões sobre práticas pedagógicas e gamificação. Foi nossa intenção abordar as possibilidades de ressignificações nas práticas pedagógicas que emergem das experiências vivenciadas por professores com a gamificação, na perspectiva da Educação Continuada em serviço. Desta forma, problematizamos fragmentos dos processos de aprendizagens dos sujeitos de pesquisa ao desenvolverem práticas pedagógicas gamificadas, por meio do experimento de formação continuada.

Foi possível demonstrar os afastamentos e aproximações da concepção de gamificação e os possíveis indícios de ressignificações que emergiram desse processo formativo. Grande parte dos sujeitos de pesquisa, inicialmente, mostraram desconhecer a concepção de gamificação como postulamos em nossos estudos: uma estratégia de metodologia ativa para desenvolver práticas pedagógicas permeadas por elementos típicos de jogos digitais (MARTINS, 2015; MARTINS, GIRAFFA, 2015; MARTINS, GIRAFFA, 2016). As análises nos apontam possíveis caminhos que as instâncias formadoras de professores, seja de base (inicial) ou em serviço, precisam considerar, tais como: tornar o professor um prático-pesquisador e desenvolver competências que despertem a reflexão e a autoeducação. O quanto essas competências e habilidades adquiridas como jogador podem (ou devem) ser incorporadas na formação docente é outra questão a ser discutida. 
A defasagem hoje existente, entre a formação de base do professor (graduação) e as demandas que lhe são impostas em face do contexto da cibercultura, especialmente no que tange à gamificação, necessitam de ações de restruturação do currículo de formação docente para que possamos ressignificar as práticas pedagógicas à luz desse novo, desafiador e promissor contexto em que as tecnologias digitais emergem como elementos coadjuvantes da atuação docente.

A reflexão que fazemos, ao concluir esta investigação, é que muitos falam em aproximar os hábitos de lazer dos hábitos de estudo, sendo a máxima "aprender se divertindo" ressignificada neste ciberespaço. No contexto da cibercultura, o ciberespaço criado pela rede Internet e seus serviços permitiu ampliar atividades e hábitos que tínhamos no espaço presencial. Os jogos sempre fizeram parte do cotidiano escolar e foram (e são amplamente) utilizados como estratégia para estudos em diferentes níveis. No entanto, a questão não se reduz apenas a mudar formato (analógico para digital); ampliam-se as possibilidades interativas, colaboração, a expressão interdisciplinar e cria-se um espaço para se trabalhar conceitos, conteúdos e construir conhecimento, tirando partido dos hábitos de lazer dos nossos estudantes, cada vez mais "jogadores". Se eles, ao jogarem RPG (Role playing games) tanto de mesa como digitais, jogos desafiadores (batalhas, conquistas de mundos, e outros) necessitam exercitar sofisticados processos cognitivos e estabelecem estratégias de colaboração e compartimento de saberes para resolverem as etapas de seus jogos e seguir adiante (as fases do jogo), por que não estimular tais capacidades para estudar? A tarefa é simples? Claro que não! Gamificar atividades de maneira a proporcionar esta aproximação requer do professor um conjunto de habilidades e competências que fazem parte daqueles habituados a jogar. Ou seja, além de ter hábitos de jogador, o docente terá de fazer a transposição didática disso para criar práticas pedagógicas que aproximem os dois mundos: o lazer do estudo formal. Logo, emerge uma questão importante: só professores jogadores teriam competência suficiente para gamificar práticas pedagógicas? Não, mas a pesquisa nos mostrou que aqueles que possuem tais experiências se mostram mais afetos a gamificar suas práticas.

Por mais que a gamificação seja recente do ponto de vista de discussão no campo da Educação, ela é uma metodologia ativa que vem sendo discutida desde 2012, em outras áreas de conhecimento. Por que ela emergiu com força no contexto educacional? Em um contexto sociocultural onde a conectividade; a ubiquidade; o acesso, a produção e o compartilhamento de informações e a velocidade das mudanças são parte do cotidiano, o professor necessita estar aberto e articulado a buscar novos conhecimentos, quer na sua educação formal, seja de graduação, pós-graduação ou Educação continuada, quer de maneira independente (autoeducação). No âmbito das escolas, a alternativa é a Educação Continuada em serviço, buscando fornecer ao docente as oportunidades de criar práticas pedagógicas em consonância com o projeto da escola. A vantagem de tal abordagem é a criação de uma cultura na escola na qual se valorizam os hábitos de lazer dos alunos e dos 
professores criando um espaço alternativo de interlocução. É importante compreender o tempo histórico de modo a expressá-lo nas práticas pedagógicas, dialogando com os comportamentos e hábitos dos estudantes.

O caminho está para ser construído porque acreditamos, ao propor o modelo, sugerir um caminho para organização das etapas e elementos a serem considerados, sem propor uma abordagem prescritiva.

\section{REFERÊNCIAS}

ALMEIDA, José Adolfo Mota de; PINTO NETO, Pedro da Cunha. A lousa digital interativa: táticas e astúcias de professores consumidores de novas tecnologias. ETD - Educação Temática Digital, Campinas, SP, v. 17, n. 2, p. 394-413, ago. 2015. ISSN 1676-2592. Disponível em: http://periodicos.sbu.unicamp.br/ojs/index.php/etd/article/view/8636465 Acesso em: 24 abr. 2016.

ALVES, Lynn Rosalina Gama. A cultura lúdica e cultura digital: interfaces possíveis. Revista Entreideias: educação, cultura e sociedade, v. 3, n. 2, 2014. Disponível em: https://portalseer.ufba.br/index.php/entreideias/article/view/7873 Acesso em: 8 jun. 2017.

BRASIL. Ministério da Educação. Diretrizes Curriculares Nacionais Gerais da Educação Básica. Brasília: MEC, SEB, DICEI, 2013. Disponível em: http://portal.mec.gov.br/index.php?option=com content\&view=article\&id=12663\&ltemid=1152 Acesso em: 19 julho 2015.

SEBASTIAN DETERDING et al. Gamification: Toward a Definition. Conference on Human Factors in Computing Systems. Vancouver: Proceedings of the SIGCHI Conference on Human Factors in Computing Systems, 2011. Disponível em: http://gamification-research.org/wpcontent/uploads/2011/04/02-Deterding-Khaled-Nacke-Dixon.pdf Acesso em: 8 jun. 2017.

HUIZINGA, Johan. Homo Ludens: o jogo como elemento da cultura. 7. ed. São Paulo: Perspectiva, 2012.

KAPP, Karl. The Gamification of Learning and Instruction: Game-based Methods and Strategies for Training and Education. San Francisco: Pfeiffer, 2012.

LALUEZA, José Luis; CRESPO, Isabel; CAMPS, Silvia. As tecnologias de informação e da comunicação e os processos de desenvolvimento e socialização. In: COLL, César; MONEREO, Carles (Org.) A Psicologia da Educação Virtual: aprender e ensinar com as Tecnologias da Informação e da Comunicação. Porto Alegre: Artmed, 2010.

LÉVY, Pierre. Cibercultura. São Paulo: Editora 34, 1999.

MCGONIGAL, Jane. Reality is broken: why games make us better and how they can change the world. Nova York: The Penguin Press, 2011.

MORAES, Roque; GALIAZZI, Maria do Carmo. Análise textual discursiva. ljuí: Ed. da UNIJUÍ, 2007. MORIN, Edgar; ALMEIDA, Maria da Conceição de; CARVALHO, Edgard de Assis. (Org.). Educação e complexidade: os sete saberes e outros ensaios. 6.ed. São Paulo: Cortez, 2013. 
MARTINS, Cristina. Gamificação nas práticas pedagógicas: um desafio para a formação de professores em tempos de cibercultura. Porto Alegre: PUCRS/PPGEdu - Escola de Humanidades, 2015. [Dissertação de Mestrado] Disponível em: http://hdl.handle.net/10923/7809 Acesso em: 8 jun. 2017.

MARTINS, Cristina; GIRAFFA, Lucia Maria Martins. Gamificação nas práticas pedagógicas: teorias, modelo e vivências. In: TISE 2015 - XX Congreso Internacional de Informática Educativa, 2015, Santiago - Chile. Nuevas Ideas en Informática Educativa Memorias del XX Congreso Internacional de Informática Educativa. Santiago de Chile: Universidad de Chile, 2015. v. 11. p. 42-53. Disponível em: http://www.tise.cl/volumen11/TISE2015/42-53.pdff Acesso em: 8 jun. 2017.

Design de práticas pedagógicas incluindo elementos de jogos digitais em atividades gamificadas. Obra Digital: journal of communication and technology, v. 10, p. 52-67, 2016. Disponível em: http://revistesdigitals.uvic.cat/index.php/obradigital/article/view/69 Acesso em: 8 jun. 2017.

PRENSKY, Marc. Aprendizagem baseada em jogos digitais. São Paulo: SENAC São Paulo, 2012.

SANTAELLA, Lucia. Comunicação Ubíqua: Repercussões na cultura e na educação. São Paulo: Editora Paulus, 2013.

SANTAELLA, Lucia; FEITOZA, Mirna. (Org.) Mapa do Jogo: A diversidade cultural do games. São Paulo: Cengage Learning, 2009.

SATO, Adriana Kei Ohashi. Do mundo real ao mundo ficcional: a imersão no jogo. In: SANTAELLA, Lucia; FEITOZA, Mirna. (Org.) Mapa do Jogo: A diversidade cultural dos games. São Paulo: Cengage Learning, 2009.

SOLÉ, Isabel; COLL, César. Os professores e a concepção construtivista. In: COLL, César; MARTíN, Elena; MAURI, Teresa; MIRAS, Mariana; ONRUBIA, Javier; SOLÉ, Isabel; ZABALA, Antoni. O construtivismo em sala de aula. São Paulo: Ática, 2003.

THIEBES, Scott; LINS, Sebastian; BASTEN, Dirk. Gamifying information systems: a synthesis of aaaaagamification mechanics and dynamics. Twenty Second European Conference on Information Systems. Tel Aviv, 2014. Disponível em: http://ecis2014.eu/E-poster/files/0278-file1.pdf Acesso em: 15 fev. 2015.

VEEN, Wim; VRAKKING, Ben. Homo Zappiens: educando na era digital. Porto Alegre: Artmed, 2009.

VIGOTSKY, Lev Semenovich. A formação social da mente: o desenvolvimento dos processos psicológicos. Org. por Michael Cole et al. 7.ed. São Paulo: Martins Fontes, 2007.

\footnotetext{
' Revisão gramatical do texto sob a responsabilidade de : Jonas Rodrigues Saraiva
} 